ISSN 1561-8323 (Print)

ISSN 2524-2431 (Online)

УДК 538.958

https://doi.org/10.29235/1561-8323-2019-63-4-430-436

Поступило в редакцию 14.06.2019

Received 14.06.2019

\author{
Член-корреспондент Ф. Ф. Комаров ${ }^{1}$, Н. С. Нечаев ${ }^{1}$, И. Н. Пархоменко ${ }^{2}$, Г. Д. Ивлев ${ }^{2}$, \\ Л. А. Власукова ${ }^{2}$, В. В. Пилько ${ }^{1}$, Э. Вендлер ${ }^{3}$, А. Ф. Комаров ${ }^{1}$ \\ ${ }^{1}$ Институт прикладных физических проблем имени А. Н. Севченко Белорусского \\ государственного университета, Минск, Республика Беларусь \\ ${ }^{2}$ Белорусский государственный университет, Минск, Республика Беларусь \\ ${ }^{3}$ Йенский университет имени Фридриха Шиллера, Йена, Германия

\section{ФОРМИРОВАНИЕ ФОТОПРИЕМНЫХ СТРУКТУР ИК-ДИАПАЗОНА ПУТЕМ ПЕРЕСЫЩЕНИЯ КРЕМНИЯ ТЕЛЛУРОМ}

\begin{abstract}
Аннотация. Слои кремния, легированные теллуром до концентраций (3-5)10 $0^{20} \mathrm{~cm}^{-3}$, получены ионной имплантацией с последующим импульсным лазерным отжигом. Показано, что 70-90 \% внедренной примеси находится в позиции замещения в решетке кремния. Слои, гиперпересыщенные теллуром, проявляют существенное поглощение (35-66 \%) в области длин волн 1100-2500 нм, причем коэффициент поглощения увеличивается с ростом длины волны. Проведено сравнение спектров поглощения имплантированных слоев после лазерного отжига, а также после равновесного и быстрого термического отжигов. Показано, что равновесный отжиг после имплантации ионов теллура увеличивает поглощение фотонов в области длин волн 1100-2500 нм на 4 \% по сравнению с неимплантированным кремнием. После быстрого термического отжига поглощение в ИК-области возрастает лишь на $2 \%$.

Ключевые слова: ИК-фотодетекторы, кремний, высокодозная имплантация ионов Те, импульсный лазерный отжиг, резерфордовское обратное рассеяние, комбинационное рассеяние света, спектры поглощения

Для цитирования: Формирование фотоприемных структур ИК-диапазона путем пересыщения кремния теллуром / Ф. Ф. Комаров [и др.] // Докл. Нац. акад. наук Беларуси. - 2019. - Т. 63, № 4. - С. 430-436. https://doi. org/10.29235/1561-8323-2019-63-4-430-436
\end{abstract}
Corresponding Member Fadei F. Komarov ${ }^{1}$, Nikita S. Nechaev' ${ }^{1}$, Irina N. Parkhomenko ${ }^{2}$, Gennadii D. Ivlev ${ }^{2}$, Liudmila A. Vlasukova ${ }^{2}$, Vladimir V. Pilko ${ }^{1}$, Elke Wendler ${ }^{3}$, Alexander F. Komarov ${ }^{1}$
${ }^{1}$ A. N. Sevchenko Institute of Applied Physical Problems of Belarusian State University, Minsk, Republic of Belarus ${ }^{2}$ Belarusian State University, Minsk, Republic of Belarus ${ }^{3}$ Friedrich-Schiller-Universität, Jena, Germany

\title{
FORMATION OF THE IR PHOTODETECTING STRUCTURES BASED ON SILICON HYPERDOPED WITH TELLURIUM
}

\begin{abstract}
The Si layers doped with Te up to the concentrations of $(3-5) 10^{20} \mathrm{~cm}^{-3}$ have been formed via ion implantation and pulsed laser melting. It is found, 70-90\% of the embedded impurity atoms are in substitution states in the silicon lattice. These layers have revealed significant absorption (35-66\%) in the wavelength $\lambda$ range of $1100-2500 \mathrm{~nm}$. In this case, the absorption coefficient increases with the $\lambda$ growth. The absorption spectra of the implanted layers after pulsed laser melting, equilibrium furnace annealing, and rapid thermal annealing have been compared. It is shown that equilibrium furnace annealing increases the photon absorption by $4 \%$ in the wavelength range of $1100-2500 \mathrm{~nm}$ in comparison with virgin $\mathrm{Si}$. After rapid thermal annealing, the photon absorption in the IR-range increases only by $2 \%$.

Keywords: IR photodetectors, Te hyperdoped with $\mathrm{Si}$, ion implantation, pulsed laser melting, Rutherford backscattering spectroscopy, Raman spectroscopy, absorption spectra

For citation: Komarov F. F., Nechaev N. S., Parkhomenko I. N., Ivlev G. D., Vlasukova L. A., Pilko V. V., Wendler E., Komarov A. F. Formation of the IR photodetecting structures based on silicon hyperdoped with tellurium. Doklady Natsional'noi akademii nauk Belarusi = Doklady of the National Academy of Sciences of Belarus, 2019, vol. 63, no. 4, pp. 430-436 (in Russian). https://doi.org/10.29235/1561-8323-2019-63-4-430-436
\end{abstract}

Введение. Кремний - основной материал микроэлектроники и значительно реже используется в оптоэлектронике. Однако поскольку кремний - непрямозонный полупроводник с шириной запрещенной зоны 1,12 эВ, излучение с длиной волны больше, чем 1100 нм, кремнием не поглощается и, соответственно, не регистрируется. По этой причине кремниевые солнечные батареи пропускают инфракрасную часть солнечного спектра (1,1-3) мкм, а кремниевые фотодетекторы 
нечувствительны к трем основным полосам оптоволоконной телекоммуникации: S (14601530 нм), C (1530-1565 нм) и L (1565-1625 нм) [1]. Для решения данных проблем ведется активный поиск недорогих и эффективных ИК-фотодетекторов, совместимых с кремниевой КМОП-технологией. К настоящему времени установлено, что наибольший коэффициент поглощения света в ИК-диапазоне при комнатной температуре $\left(\sim 10^{4} \mathrm{~cm}^{-1}\right)$ наблюдается у кремния, пересыщенного халькогенами (S, Se, Te) [2].

Равновесная растворимость халькогенов в кремнии составляет $\sim 10^{16} \mathrm{~cm}^{-3}$. При таких концентрациях халькогены создают глубокие уровни в запрещенной зоне кремния. Однако при превышении равновесной растворимости на 4-5 порядков примесные уровни сливаются в подзону. Становится возможным поглощение фотонов через электронные переходы «валентная зона примесная подзона» и «примесная подзона - зона проводимости». [3]. Чтобы добиться гиперпересыщения, легирование кремния халькогенами проводят с использованием неравновесных методов, таких как ионная имплантация с последующим фото-, пико-, наносекундным лазерным [2] или флэш отжигом [4].

В 1961 г. Шокли и Куизер показали, что теоретический предел эффективности кремниевых солнечных батарей составляет 41 \% [5]. Позже, используя тот же подход, авторы работы [6] показали, что теоретический предел эффективности солнечных батарей на основе модифицированного кремния с примесной подзоной составляет $63 \%$. Таким образом, предельная эффективность солнечных батарей на основе кремния, пересыщенного халькогенами, может быть в полтора раза больше, чем для классических кремниевых батарей.

Следует отметить, что для дальнейшей миниатюризации кремниевых устройств необходимо получить кремний со сверхвысокими концентрациями свободных электронов $\sim 10^{21} \mathrm{~cm}^{-3}$ [7]. В настоящее время высокую концентрацию свободных электронов получают легированием кремния примесями, создающими мелкие уровни в запрещенной зоне кремния (например, элементами V группы Периодической системы - P, As и Sb). У этих примесей небольшая энергия активации (20-50 мэВ), малый коэффициент диффузии и достаточно большой предел равновесной растворимости в кремнии. Однако даже при легировании кремния этими примесями до концентраций, превышающих равновесный предел растворимости, не удается получить концентрацию свободных электронов выше $\sim 5 \cdot 10^{20} \mathrm{~cm}^{-3}$ [8]. Недавно установлено, что примеси (например, халькогены), создающие в кремнии глубокие уровни с энергией ионизации в несколько сотен мэВ, могут индуцировать свободные электроны в кремнии до концентраций выше $10^{20} \mathrm{~cm}^{-3}$. Этот процесс сопровождается так называемым переходом «изолятор-проводник», когда примесная подзона перекрывается с зоной проводимости [9]. При этом концентрация свободных электронов линейно возрастает с увеличением концентрации примеси, а доля электрически активированной примеси (находящейся в узлах решетки $\mathrm{Si}$ ) остается практически неизменной [10]. B [11] показано, что Si, гиперпересыщенный теллуром, остается стабильным после термообработки при $500{ }^{\circ} \mathrm{C}$ в течение 10 мин. Следовательно, такой материал может быть использован в рамках современной планарной КМОП технологии производства микросхем.

В данной работе исследовались структурные и оптические свойства кремния, гиперпересыщенного теллуром, методом ионной имплантации с последующей термообработкой.

Материалы и методы исследования. Пластины $\mathrm{Si}$ (111) $p$-типа проводимости с удельным сопротивлением $\rho=10$ Ом $\cdot$ см, полированные с двух сторон, были имплантированы ионами $\mathrm{Te}^{+}$ с энергией 200 кэВ дозой $1 \cdot 10^{16} \mathrm{~cm}^{-2}$. Затем в целях сравнения проводилось три вида термических обработок: печной отжиг в атмосфере аргона при температуре $900{ }^{\circ} \mathrm{C}$ в течение 30 мин, быстрый термический отжиг (БТО) при температуре $1200^{\circ} \mathrm{C}$ в течение 3 мин и импульсный лазерный отжиг (ИЛО) рубиновым лазером ( $\lambda=694$ нм, длительность отжига $\approx 70$ нс по уровню 0,5

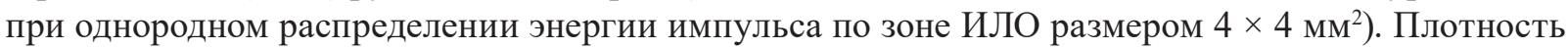
энергии $W$ в лазерном импульсе (зоне ИЛО) задавалась равной $1,5,2$ и 2,5 Дж/см².

Анализ распределения внедренной примеси по глубине, доли атомов теллура в узлах решетки кремния и степени кристалличности имплантированных слоев проводился методом регистрации спектров резерфордовского обратного рассеяния (РОР) ионов $\mathrm{He}^{+}$с энерией 1,5 МэВ в режиме каналирования (POP/К) и без него. Моделирование спектров РОР с помощью програм- 
мы SIMNRA [12] выполнялось ступенчато до полного совпадения с экспериментальными спектрами. Для исследования оптических свойств снимались спектры комбинационного рассеяния света (КРС), пропускания $(T)$ и отражения $(R)$. Спектры КРС регистрировались в геометрии обратного рассеяния на микро-рамановском спектрометре Ramanor U1000 (Jobin Yvon) при возбуждении лазером с длиной волны 532 нм. Спектры пропускания и отражения снимались на спектрофотометре Lambda 1050 WB (PerkinElmer) в диапазоне 200-2500 нм. Спектр поглощения $(A)$ рассчитывался по формуле

$$
A=100 \%-R-T \text {. }
$$

Результаты и их обсуждение. На рис. 1 представлены спектры РОР и РОР/К. Как видно из рисунка, печной отжиг приводит к значительной диффузии Те к поверхности. После ИЛО наблюдается диффузия примеси как в глубь образца, так и к поверхности. После БТО примеси атомов Те в образце не обнаружено.

На рис. 2 представлены концентрационные профили, полученные путем моделирования в программе SIMNRA до полного совпадения экспериментальных и моделированных спектров. Показан также концентрационный профиль внедренной примеси, моделированный с использованием программы BEAM2HD [13]. Следует отметить хорошее количественное соответствие данных теории и эксперимента как по положению максимума концентрации, так и по величине концентрации как функции глубины во всем диапазоне концентраций, регистрируемых резерфордовским обратным рассеянием. Сразу после имплантации концентрация теллура в максимуме на глубине $\sim 80$ нм составляет $\sim 1 \cdot 10^{21} \mathrm{~cm}^{-3}$. В результате печного отжига максимум концентрации теллура сдвигается к поверхности до глубины $\sim 60$ нм, концентрация примеси в максимуме составляет $9 \cdot 10^{20} \mathrm{~cm}^{-3}$. На поверхности концентрация теллура при этом превышает $1 \cdot 10^{21} \mathrm{~cm}^{-3}$. По-другому происходит перераспределение примеси после ИЛО. После лазерной обработки при $W=1,5$ Дж/см² в области глубин от поверхности до 190 нм формируется концентрационное плато, концентрация теллура в котором достигает $5 \cdot 10^{20} \mathrm{~cm}^{-3}$. При плотностях энергии лазерного импульса 2,0 и 2,5 Дж/см концентрация теллура в области плато снижается до $3 \cdot 10^{20} \mathrm{~cm}^{-3}$ за счет диффузии части примеси в глубь образца до глубин 300 и 330 нм после ИЛО с $W=2,0$ и 2,5 Дж/см² соответственно.

Для оценки степени кристалличности $\mathrm{Si}$ и доли Те в позициях замещения в решетке $\mathrm{Si}$ использованы величины $\chi^{\mathrm{Si}}$ и $\chi^{\mathrm{Te}}$, которые показывают интегральные отношения отсчетов канали-

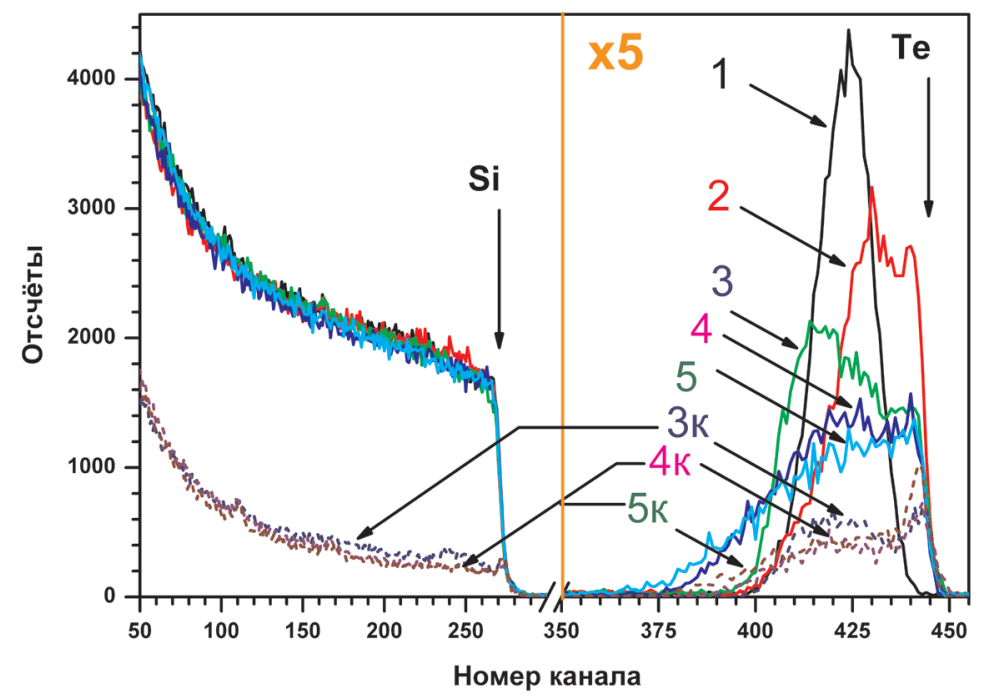

Рис. 1. Спектры РОР образцов $\mathrm{Si}$, гиперпересыщенного Те: 1 - исходный, 2 - после отжига при $T=900{ }^{\circ} \mathrm{C}, 30$ мин.

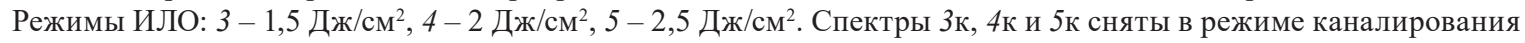

Fig. 1. RBS spectra of the Te-implanted Si samples: 1 - as-implanted, 2 - after annealing at $T=900{ }^{\circ} \mathrm{C}, 30 \mathrm{~min}$. Regimes of pulse laser annealing: $3-1.5 \mathrm{~J} / \mathrm{cm}^{2}, 4-2 \mathrm{~J} / \mathrm{cm}^{2}, 5-2.5 \mathrm{~J} / \mathrm{cm}^{2}$. The spectra $3 \kappa, 4 \kappa$ and $5 \kappa$ were registered in channeling regime 


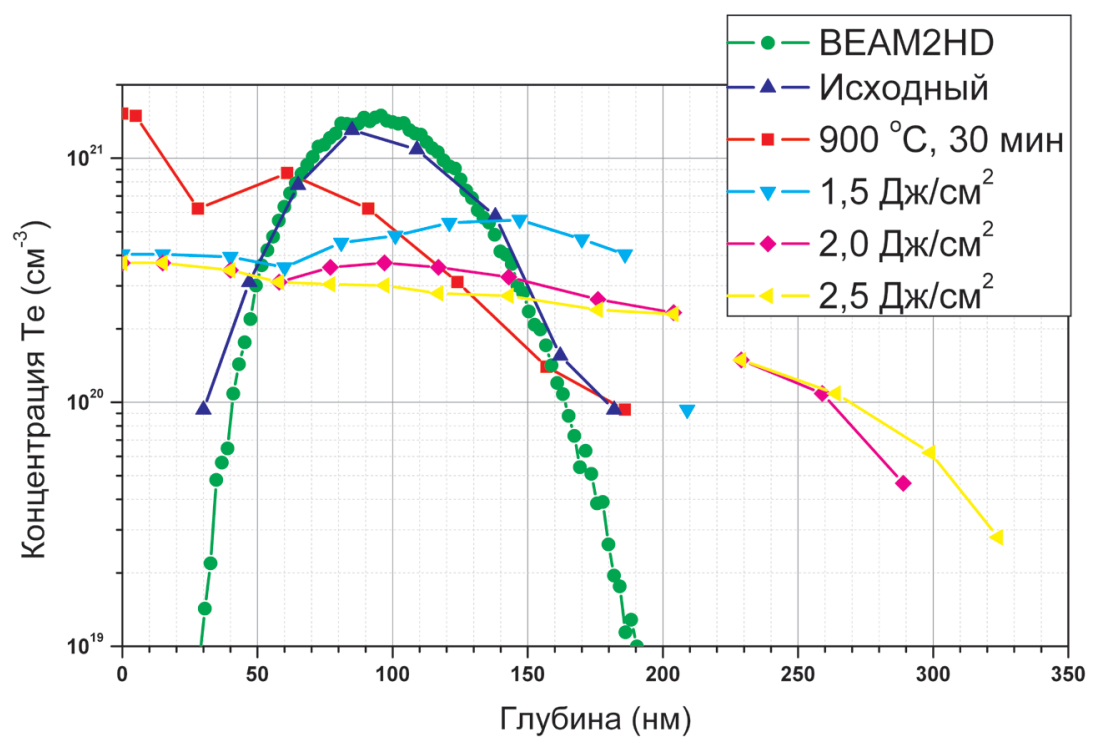

Рис. 2. Смоделированный профиль концентрации атомов теллура и экспериментальные концентрационные профили атомов теллура для имплантированного образца $\mathrm{Si}$ без отжига и для различных режимов термообработки

Fig. 2. Simulated Te concentration depth profile and experimental Te concentration depth profiles for the implanted silicon samples before and after different treatment

рованного к неориентированному спектру в каналах, связанных с Si и Те соответственно. Доля атомов примеси в узлах решетки кремния $f$ рассчитывалась по формуле из работы [14]

$$
f=\left(1-\chi^{\mathrm{Te}}\right) /\left(1-\chi^{\mathrm{Si}}\right) .
$$

Значения $\chi^{\mathrm{Si}}$ и $f$ представлены в таблице.

Значения $\chi^{\mathrm{Si}}$ и $\boldsymbol{f}$ образцов $\mathrm{Si}$, гиперпересыщенного Те

The values of $\chi^{\mathrm{Si}}$ and $f$ for Te-implanted Si

\begin{tabular}{|c|c|c|c|}
\hline $\begin{array}{l}\text { Параметр } \\
\text { Parameter }\end{array}$ & 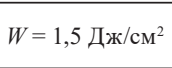 & $W=2,0$ Дж $/ \mathrm{cm}^{2}$ & $W=2,5$ Дж $/ \mathrm{cm}^{2}$ \\
\hline$\chi^{\mathrm{Si}}, \%$ & 23,9 & 23,1 & 21,2 \\
\hline$f, \%$ & 91,2 & 90,4 & 73,6 \\
\hline
\end{tabular}

Как видно из таблицы, диапазон значений $\chi^{\mathrm{Si}}$ кремния, гиперпересыщенного теллуром, после ИЛО составляет $23,9-21,2 \%$, причем с ростом плотности энергии в импульсе $\chi^{\mathrm{Si}}$ снижается. Для сравнения, в идеальном монокристалле $\chi^{\mathrm{Si}} \leq 5 \%$, а в полностью аморфном материале $\chi^{\mathrm{Si}}=100 \%$ [14]. Таким образом, степень кристалличности гиперпересыщенного кремния максимальна после лазерного отжига с максимальной плотностью энергии $W=2,5$ Дж/см². Анализ спектров РОР в режиме каналирования свидетельствует о том, что лазерный отжиг приводит также к вхождению Те в узлы решетки кремния, причем степень активации примеси очень высока и составляет 91,2-73,6 \%. При этом, чем меньше энергия ИЛО, тем больше примеси оказывается в позициях замещения в решетке кремния.

На рис. 3 представлены спектры КРС образцов имплантированного кремния до и после термообработок. Спектр исходной кремниевой пластины характеризуется узкой симметричной полосой с максимумом при $520 \mathrm{~cm}^{-1}$, обусловленной рассеянием на оптическом фононе. После имплантации данная полоса исчезает, что говорит о полной аморфизации имплантированного слоя кремния. После проведения равновесного термического отжига полоса вновь регистрируется, что свидетельствует о восстановлении кристаллической структуры легированного слоя кремния. Причем, судя по спектральному положению и интенсивности данной полосы, уровень остаточного напряжения меньше для образца, прошедшего БТО, чем для образца после длительной печной обработки при $900{ }^{\circ} \mathrm{C}$. Для образца, облученного лазерным импульсом с $W=1,5$ Дж/см${ }^{2}$, также 


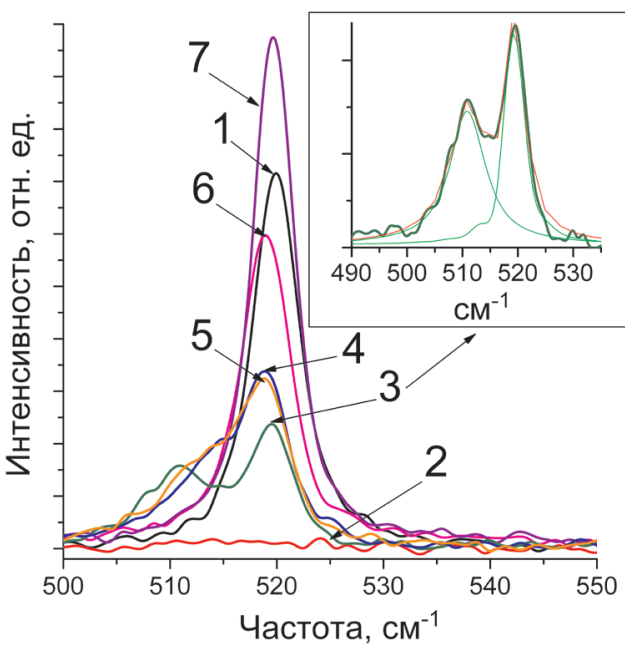

Рис. 3. Спектры комбинационного рассеяния света исходной кремниевой пластины (1), кремния, имплантированного Те до (2) и после лазерного отжига импульсами с плотностью энергий 1,5 (3), 2 (4), 2,5 (5) Дж/см², после печного отжига при $900{ }^{\circ} \mathrm{C}$ в 30 мин (6), после БТО при $1200{ }^{\circ} \mathrm{C}$ в течение 3 мин (7)

Fig. 3. Raman spectra of the Si substrate (1), Te implanted silicon before (2) and after laser annealing by pulses with energy densities 1.5 (3), 2 (4), 2.5 (5) $\mathrm{J} / \mathrm{cm}^{2}$, after furnace annealing at $900{ }^{\circ} \mathrm{C}$ for $30 \mathrm{~min}(6)$, after rapid thermal annealing at $1200{ }^{\circ} \mathrm{C}$ for $3 \min (7)$ плантированных образцах после ИЛО наблюдается интенсивное поглощение света с энергией меньшей, чем ширина запрещенной зоны кремния. При этом для образца после лазерного отжига с $W=1,5$ Дж/см² коэффициент поглощения увеличивается с $34 \%$ при $\lambda=1180$ нм до $55 \%$ при $\lambda=2500$ нм. Эффект возрастания коэффициента поглощения с ростом длины волны для образ-

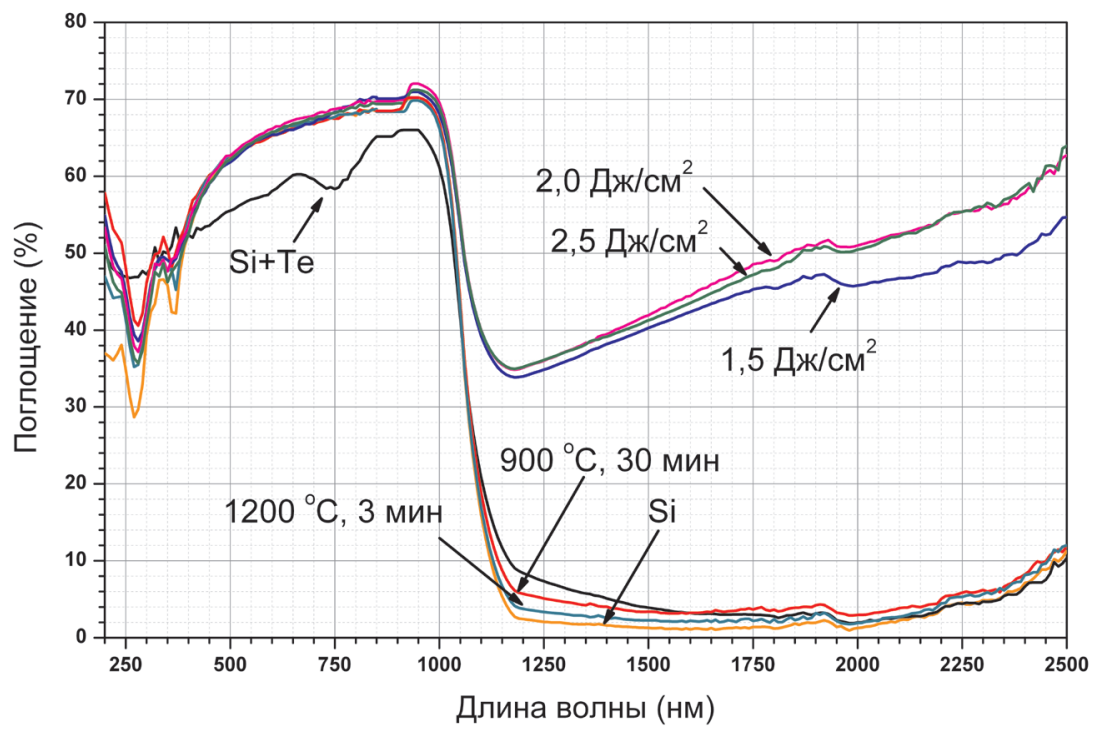

Рис. 4. Спектры поглощения образцов исходного кремния и имплантированных теллуром до и после термообработки в различных режимах

Fig. 4. Absorption spectra of the virgin Si substrate and Te-implanted silicon before and after annealing at different regimes

регистрируется сигнал от кремниевой матрицы, причем спектр КРС в обсуждаемой спектральной области можно аппроксимировать двумя полосами: слабая полоса с максимумом при $511 \mathrm{~cm}^{-1}$ и более интенсивная при $519,7 \mathrm{~cm}^{-1}$. Проявление данных полос указывает на наличие двух рекристаллизованных слоев с разным уровнем остаточных напряжений. Это может быть обусловлено разной скоростью рекристаллизации слоев кремния с различным уровнем легирующей примеси. Повышение энергии в импульсе (2-2,5 Дж/см²) приводит к сдвигу низкочастотной полосы в сторону больших частот. Таким образом, с увеличением энергии в импульсе возрастает степень структурного совершенства рекристаллизованного слоя имплантированного кремния, однако полного восстановления структуры не происходит.

На рис. 4 представлены спектры поглощения имплантированных образцов в диапазоне длин волн 2502500 нм.

Как видно, для образца сразу после имплантации $(« \mathrm{Si}+\mathrm{Te»)} \mathrm{наблюдается} \mathrm{уменьшение} \mathrm{коэффициента} \mathrm{по-}$ глощения в видимой области и его увеличение на 1-6 \% в области 1100-2000 нм. Данный эффект, предположительно, вызван поглощением ИК излучения на радиационных дефектах. Печной отжиг увеличивает поглощение фотонов с $\lambda>1100$ нм на 4 \% по сравнению с кристаллическим кремнием. В образце после БТО поглощение ИК фотонов увеличено лишь на $2 \%$. В то же время в им.

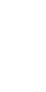


цов после ИЛО с $W=2,0$ и 2,5 Дж/см² выражен еще заметнее. В этом случае коэффициент поглощения увеличивается с $35 \%$ при $\lambda=1180$ нм до 64 и $65 \%$ соответственно при $\lambda=2500$ нм.

Заключение. Имплантацией ионов Те с энергией 200 кэВ дозой $1 \cdot 10^{16} \mathrm{~cm}^{-2}$ с последующим наносекундным лазерным отжигом при плотности энергии в импульсе $1,5-2,5$ Дж/см ${ }^{2}$ получены слои кремния, гиперпересыщенные теллуром до концентрации (3-5)1020 $\mathrm{cm}^{-3}$. По данным РОР, внедренная примесь практически равномерно распределена в имплантированном слое на глубине от поверхности до 190 нм. При этом 70-90 \% внедренной примеси находится в позиции замещения в решетке кремния.

В кремнии, гиперпересыщенном теллуром, наблюдается эффективное поглощение фотонов с энергией меньше ширины запрещенной зоны кремния, т. е. в области длин волн $\lambda>1100$ нм, вплоть до предельно измеренной $\lambda=2500$ нм. При этом в сравнении с нелегированным кристаллическим кремнием коэффициент поглощения увеличивается с 34-35 \% при $\lambda=1180$ нм до 55$65 \%$ при $\lambda=2500$ нм. Это вызвано хорошей рекристаллизацией имплантированного слоя кремния вследствие лазерного отжига и внедрения 70-90 \% примеси в позицию замещения в кристаллической решетке кремния. Полученные структуры, несомненно, представляют интерес как в качестве фотоприемных в ИК диапазоне длин волн, так и при изготовлении эффективных солнечных элементов на кремнии. Показано, что равновесный печной отжиг после ионной имплантации приводит к увеличению поглощения ИК фотонов только на $4 \%$ по сравнению с кристаллическим кремнием. После БТО поглощение ИК света возрастает лишь на 2 \%. Это обусловлено как дезактивацией атомов внедренной примеси (уход из узлов кристаллической решетки), так и выходом значительной части внедренной примеси через поверхностный слой во время длительных термообработок.

\section{Список использованных источников}

1. Visible and near-infrared responsivity of femtosecond-laser microstructured silicon photodiodes / J. E. Carey [et al.] // Opt. Lett. - 2005. - Vol. 30, N 14. - P. 1773-1775. https://doi.org/10.1364/ol.30.001773

2. Fabrication and subband gap optical properties of silicon supersaturated with chalcogens by ion implantation and pulsed laser melting / B. Bob [et al.] // J. Appl. Phys. - 2010. - Vol. 107 - Art. 123506. https://doi.org/10.1063/1.3415544

3. Schibli, E. Deep impurities in silicon / E. Schibli, A. G. Milnes // Materials Science and Engineering. - 1967. - Vol. 2, N 4. - P. 173-180. https://doi.org/10.1016/0025-5416(67)90056-0

4. Room-temperature short-wavelength infrared Si photodetector / Y. Berencén [et al.] // Sci. Rep. - 2017. - Vol. 7, N 1. Art. 43688. https://doi.org/10.1038/srep43688

5. Shockley, W. Detailed balance limit of efficiency of $p-n$ junction solar cells / W. Shockley, H. J. Queisser // J. Appl. Phys. - 1961. - Vol. 32, N 3. - P. 510-519. https://doi.org/10.1063/1.1736034

6. Luque, A. Increasing the efficiency of ideal solar cells by photon induced transitions at intermediate levels / A. Luque, A. Martí // Phys. Rev. Lett. - 1997. - Vol. 78, N 26. - P. 5014-5017. https://doi.org/10.1103/physrevlett.78.5014

7. Gossmann, H. J. Junctions for deep sub-100 nm MOS: How far will ion implantation take us? / H. J. Gossmann, C. S. Rafferty, P. Keys // MRS Proceedings. - 2000. - Vol. 610. - P. B1.2.1-B1.2.10. https://doi.org/10.1557/proc-610-b1.2

8. Gossmann, H. J. Doping of Si thin films by low temperature molecular beam epitaxy / H. J. Gossmann, F. C. Unterwald, H. S. Luftman // J. Appl. Phys. - 1993. - Vol. 73, N 12. - P. 8237-8241. https://doi.org/10.1063/1.353441

9. Insulator-to-Metal Transition in Selenium-Hyperdoped Silicon: Observation and Origin / E. Ertekin [et al.] // Phys. Rev. Lett. - 2012. - Vol. 108, N 2. - Art. 026401. https://doi.org/10.1103/physrevlett.108.026401

10. Hyperdoping silicon with selenium: solid vs. liquid phase epitaxy / S. Zhou [et al.] // Sci. Rep. - 2015. - Vol. 5, N 1. Art. 8329. https://doi.org/10.1038/srep08329

11. Thermal stability of Te-hyperdoped Si: Atomic-scale correlation of the structural, electrical and optical properties / M. Wang [et al.] // Phys. Rev. Materials. - 2019. - Vol. 3, N 4. - Art. 044606. https://doi.org/10.1103/physrevmaterials.3.044606

12. Mayer, M. SIMNRA User's Guide / M. Mayer. - Garching, 1997. - 62 p.

13. Simulation of the process of high dose ion implantation in solid targets / A. F. Komarov [et al.] // Nukleonika. - 1999. Vol. 44, N 2. - P. 363-368.

14. Feldman, L. C. Materials analysis by ion channeling: Submicron crystallography / L. C. Feldman, J. W. Mayer, S. T. Picraux. - New York, 1982. -300 p.

\section{References}

1. Carey J. E., Crouch C. H., Shen M., Mazur E. Visible and near-infrared responsivity of femtosecond-laser microstructured silicon photodiodes. Optics Letters, 2005, vol. 30, no. 14, pp. 1773-1775. https://doi.org/10.1364/ol.30.001773

2. Bob B., Kohno A., Charnvanichborikarm S., Warrender J. M., Umezu I., Tabbal M., Williams J. S., Aziz M. J. Fabrication and subband gap optical properties of silicon supersaturated with chalcogens by ion implantation and pulsed laser melting. Journal of Applied Physics, 2010, vol. 107, art. 123506. https://doi.org/10.1063/1.3415544 
3. Schibli E., Milnes A. G. Deep impurities in silicon. Materials Science and Engineering, 1967, vol. 2, no. 4, pp. 173180. https://doi.org/10.1016/0025-5416(67)90056-0

4. Berencén Y., Prucnal S., Liu F., Skorupa I., Hübner R., Rebohle L., Zhou Sh., Schneider H., Helm M., Skorupa W. Room-temperature short-wavelength infrared Si photodetector. Scientific Reports, 2017, vol. 7, no. 1, art. 43688. https://doi. org/10.1038/srep43688

5. Shockley W., Queisser H. J. Detailed balance limit of efficiency of $p-n$ junction solar cells. Journal of Applied Physics, 1961, vol. 32, no. 3, pp. 510-519. https://doi.org/10.1063/1.1736034

6. Luque A., Martí A. Increasing the efficiency of ideal solar cells by photon induced transitions at intermediate levels. Physical Review Letters, 1997, vol. 78, no. 26, pp. 5014-5017. https://doi.org/10.1103/physrevlett.78.5014

7. Gossmann H. J., Rafferty C. S., Keys P. Junctions for deep sub-100 nm MOS: How far will ion implantation take us? MRS Proceedings, 2000, vol. 610, pp. B1.2.1-B1.2.10. https://doi.org/10.1557/proc-610-b1.2

8. Gossmann H. J., Unterwald F. C., Luftman H. S. Doping of Si thin films by low temperature molecular beam epitaxy. Journal of Applied Physics, 1993, vol. 73, no. 12, p. 8237-8241. https://doi.org/10.1063/1.353441

9. Ertekin E., Winkler M. T., Recht D., Said A. J., Aziz M. J., Buonassisi T., Grossma J. C. Insulator-to-Metal Transition in Selenium-Hyperdoped Silicon: Observation and Origin. Physical Review Letters, 2012, vol. 108, no. 2, art. 026401. https:// doi.org/10.1103/physrevlett.108.026401

10. Zhou S., Liu F., Prucnal S., Gao K., Khalid M., Baehtz C., Posselt M., Skorupa W., Helm M. Hyperdoping silicon with selenium: solid vs. liquid phase epitaxy. Scientific Reports, 2015, vol. 5, no. 1, art. 8329. https://doi.org/10.1038/srep08329

11. Wang M., Hübner R., Xu C., Xie Y., Berencén Y., Heller R., Rebohle L., Helm M., Prucnal S., Zhou S. Thermal stability of Te-hyperdoped Si: Atomic-scale correlation of the structural, electrical and optical properties. Physical Review Materials, 2019, vol. 3, no. 4, art. 044606. https://doi.org/10.1103/physrevmaterials.3.044606

12. Mayer, M. SIMNRA User's Guide. Garching, 1997. 62 p.

13. Komarov A. F., Komarov F. F., Żukowski P., Karwat C., Shukan A. L. Simulation of the process of high dose ion implantation in solid targets. Nukleonika, 1999, vol. 44, no. 2, pp. 363-368.

14. Feldman L. C., Mayer W., Picraux S. T. Materials analysis by ion channeling: Submicron crystallography. New York, 1982. $300 \mathrm{p}$.

\section{Информация об авторах}

Комаров Фадей Фадеевич - член-корреспондент, д-р физ.-мат. наук, заведующий лабораторией. Институт прикладных физических проблем им. А. Н. Севченко БГУ (ул. Курчатова, 7, 220045, Минск, Республика Беларусь). E-mail: komarovf@bsu.by.

Нечаев Никита Сергеевич - стажер младшего научного сотрудника. Институт прикладных физических проблем им. А. Н. Севченко БГУ (ул. Курчатова, 7, 220045, Минск, Республика Беларусь). E-mail: nsnechaev@gmail.com.

Пархоменко Ирина Николаевна - канд. физ.-мат. наук, ст. науч. сотрудник. Белорусский государственный университет (ул. Курчатова, 5, 220045, Минск, Республика Беларусь). E-mail: parkhomenko@bsu.by.

Ивлев Геннадий Дмитриевич - канд. физ.-мат. наук, вед. науч. сотрудник. Белорусский государственный университет (ул. Курчатова, 7, 220045, Минск, Республика Беларусь). E-mail: ivlev-1947@mail.ru.

Власукова Людмила Александровна - канд. физ.-мат. наук, заведующий лабораторией. Белорусский государственный университет (ул. Курчатова, 5, 220045, Минск, Республика Беларусь). E-mail: vlasukova@bsu.by.

Пилько Владимир Владимирович - мл. науч. сотрудник. Институт прикладных физических проблем им. А. Н. Севченко БГУ (ул. Курчатова, 7, 220045, Минск, Республика Беларусь). E-mail: pilkowladimir@gmail.com.

Вендлер Эльке - профессор. Йенский университет им. Ф. Шиллера (пл. М. Вина, 1, 07743, Йена, Германия). E-mail: elke.wendler@uni-jena.de.

Комаров Александр Фадеевич - д-р физ.-мат. наук, гл. науч. сотрудник. Институт прикладных физических проблем им. А. Н. Севченко БГУ (ул. Курчатова, 7, 220045, Минск, Республика Беларусь). E-mail: komarovaf@bsu.by.

\section{Information about the authors}

Komarov Fadey Fadeevich - Corresponding Member, D. Sc. (Physics and Mathematics), Professor, Head of the Laboratory. A. N. Sevchenko Institute of Applied Physical Problems of Belarusian State University (7, Kurchatov Str., 220045, Minsk, Republic of Belarus). E-mail: komarovf@bsu.by.

Nechaev Nikita Sergeevich - Junior researcher Intern. A. N. Sevchenko Institute of Applied Physical Problems of Belarusian State University (7, Kurchatov Str., 220045, Minsk, Republic of Belarus). E-mail: nsnechaev@gmail.com.

Parkhomenko Irina Nikolaevna - Ph. D. (Physics and Mathematics), Senior researcher. Belarusian State University (5, Kurchatov Str., 220045, Minsk, Republic of Belarus). E-mail: parkhomenko@bsu.by.

Ivlev Gennadii Dmitrievich - Ph. D. (Physics and Mathematics), Leading researcher. Belarusian State University (5, Kurchatov Str., 220045, Minsk, Republic of Belarus). E-mail: ivlev-1947@mail.ru.

Vlasukova Liudmila Aleksandrovna - Ph. D. (Physics and Mathematics), Head of the Laboratory. Belarusian State University (5, Kurchatov Str., 220045, Minsk, Republic of Belarus). E-mail: vlasukova@bsu.by.

Pilko Vladimir Vladimirovich - Junior researcher. A. N. Sevchenko Institute of Applied Physical Problems of Belarusian State University (7, Kurchatov Str., 220045, Minsk, Republic of Belarus). E-mail: pilkowladimir@gmail.com.

Wendler Elke - Professor. Friedrich-Schiller-Universität (1, Max Wein Platz, 07743, Jena, Germany). E-mail: elke. wendler@uni-jena.de.

Komarov Alexander Fadeevich - D. Sc. (Physics and Mathematics), Chief researcher. A. N. Sevchenko Institute of Applied Physical Problems of Belarusian State University (7, Kurchatov Str., 220045, Minsk, Republic of Belarus). E-mail: komarovaf@bsu.by. 